\title{
STUDY INTO DYNAMIC BEHAVIOUR OF THE METHYLENE BLUE ADSORPTION ON ACTIVATED CARBON
}

\author{
Alica PASTIEROVÁ ${ }^{1}$, Maroš SIROTIAK ${ }^{1}$ \\ ${ }^{1}$ SLOVAK UNIVERSITY OF TECHNOLOGY IN BRATISLAVA \\ FACULTY OF MATERIALS SCIENCE AND TECHNOLOGY IN TRNAVA \\ INSTITUTE OF INTEGRATED SAFETY \\ UliCA JÁNA BOTTU 2781/25, 91724 TRNAVA, SLOVAK REPUBLIC \\ e-mail: alica.pastierova@stuba.sk,maros.sirotiak@stuba.sk \\ Received 26 April 2021, Accepted 1 June 2021, Published 20 July 2021
}

\begin{abstract}
This paper presents a study into dynamic behaviour of the methylene blue adsorption (MB) on activated carbon. Effect of four parameters were studied: effect of the adsorbent dosage, effect of contact time, effect of $\mathrm{pH}$, and effect of the initial concentration of methylene blue. The adsorption kinetic data were modelled using the pseudo-first and pseudo-second orders. Results show that, based on the experimental data, the pseudo-second order could be considered satisfactory. Thermodynamic parameters proved that adsorption of dye was spontaneous owing to increase in temperature and endothermic nature. Taguchi method was applied to determine the optimum conditions for removal of methylene blue by activated carbon. The optimum conditions were found to be $\mathrm{pH}=7$, contact time $60 \mathrm{~min}$, initial concentration of $M B 4 \mathrm{mg} / \mathrm{L}$.
\end{abstract}

\section{Keywords}

Adsorption, dye removal, Taguchi, kinetics, thermodynamic

\section{INTRODUCTION}

With the increase in global populations and developments, extensive pressure on industries also keeps increasing. Many chemical industries, such as pharmaceutical, textile, polymers, refineries, plastic, and leather use diverse types of dyes. Usually, their industrial processes discharge $30-40 \%$ of dyes which remain in the wastewaters, whereas around $20 \%$ of wastewater worldwide comes from fabric dyeing and treatment [1].

Dyes used for textile materials are classified into two types: natural dyes, and synthetic dyes. The dyes molecules are chemically stable, difficult to biodegradable naturally, carcinogenic, hazardous and highly-toxic, and may cause serious threat not only to human health, but also to marine life. Even at low concentrations [1,2], dyes can reduce sunlight 
transmission. Dyes molecules in wastewater lead to mutagenicity, carcinogenicity and dysfunction of human beings' kidney, liver, brain, reproductive system and central nervous system [3].

\begin{tabular}{|l|l|l|}
\hline \multicolumn{3}{|l|}{ Table 1 Selected dyes and their hazardous health properties [4, 5] } \\
\hline Dyes & Textile industrial products & Health effects on skin \\
\hline $\begin{array}{l}\text { Acid dyes (congo red, methyl orange } \\
\text { acid blue) }\end{array}$ & nylon, polyamide, acrylic & skin irritation \\
\hline $\begin{array}{l}\text { Basic red, malachite green, methylene } \\
\text { blue }\end{array}$ & nylon, silk, polyester & $\begin{array}{l}\text { carcinogenic, allergic } \\
\text { reaction, skin irritation }\end{array}$ \\
\hline Direct black, direct blue, direct violet & leather, cotton, rayon & carcinogenic \\
\hline Reactive red, remazol & nylon, wool, cotton & allergic reaction \\
\hline
\end{tabular}

Azo dyes are one of the largest groups of synthetic colorants used in the industry. They are characterized by the presence of the nitrogen-nitrogen bond $(-\mathrm{N}=\mathrm{N}-)$ in the centre, and hence they are highly electron deficient. Many Azo dyes are also highly poisonous to the ecosystem and mutagens, meaning they can have acute to chronic effects upon organisms, depending on exposure time and Azo dye concentration [4]. Azo dye methylene blue (MB) $\left(\mathrm{C}_{16} \mathrm{H}_{18} \mathrm{~N}_{3} \mathrm{SCl}\right)$ is the most commonly used substance for dying cotton, wood, and silk. MB is not regarded as acutely toxic, but it can have various harmful effects. Methylene blue is widely used to evaluate the adsorption performances of activated carbons (ACs). ACs must possess a large volume of micropores with an appropriate pore size distribution, in order to adsorb molecules of different sizes. Moreover, an appropriate proportion of mesopores is required to facilitate the access to micropores.

Therefore, it is important to use treatment strategies and constantly develop new sorbents that are not only efficient, but also suitable for industrial use, economically advantageous, and environmentally friendly. In recent years, various methods to remove pollutants have been used, including the latest technologies in industry, physics, chemistry and biology. Several natural materials of biological origin are used in sorption. It is an alternative process for the effective removal of dyes from wastewater. Research has shown that sorption is one of the most costeffective and efficient methods of removing dyes from aqueous solutions.

Several conventional techniques have been used for removal dyes from wastewater, including coagulation, flocculation, oxidation, adsorption, membrane separation, biological, and electrochemical methods. Adsorption method is considered one of the most superior methods adopted for removing toxic dyes from their aqueous solutions [1]. Activated carbons are widely used as adsorbents for the removal of dyes from wastewater.

\section{MATERIALS AND METHODS}

\section{Activated carbon preparation}

A sample of activated carbon was prepared by a modified method from powdered biomass (oak). Low flow of nitrogen was permitted to pass through the system. The furnace was then heated to the final carbonization temperature. During this step, all the volatile materials were repelled out of the system. After carbonization time, the system was allowed to cool overnight [5]. The biomass was introduced to a stainless steel autoclave reactor. Carbonization took place under the nitrogen atmosphere with continuous physical activation at elevated pressure with a temperature increase of $10{ }^{\circ} \mathrm{C} / \mathrm{min}$ to $\mathrm{T}_{1}=300{ }^{\circ} \mathrm{C}$ with a residence time of 2 hours and subsequent increase to $\mathrm{T}_{2}=850^{\circ} \mathrm{C}$ with a residence time of 2 hours. After carbonization time, the system was allowed to cool overnight. 


\section{Batch adsorption experiments}

The adsorption process on a porous adsorbent generally involves several transport stages of external diffusion, internal diffusion, and actual adsorption. Although many theoretical model equations have been proposed to describe the adsorption kinetics based on mass balance, pore diffusion rate and initial/boundary conditions, these equations are not only complicated and impractical in industry, but also require detailed data such as the characteristics of adsorbate and adsorbent. In this study, pseudo-first-order and pseudo-second-order were applied [6, 7]. The conformity between experimental data and the model predicted values was expressed by the correlation coefficient $\left(\mathrm{R}^{2}\right.$, values close or equal to 1)[6]. Adsorption kinetics were conducted using two different initial MB concentrations and time from $5-360 \mathrm{~min}$ at $30{ }^{\circ} \mathrm{C}$.

Thermodynamic adsorption experiments were carried out at the temperature range of $30-60{ }^{\circ} \mathrm{C}$ at the $\mathrm{pH} 4$, concentration of $\mathrm{MB} 4 \mathrm{mg} / \mathrm{L}$ and time $60 \mathrm{~min}$. Thermodynamic parameters were calculating according to the equations:

$$
\Delta G=-R T \ln K_{L}
$$

where $R$ is the universal constant of ideal gases $(8.314 \mathrm{~J} / \mathrm{mol} / \mathrm{K}), T$ is the absolute temperature in Kelvin, and $K_{L}$ is the distribution coefficient.

In order to understand the nature of adsorption, the Gibbs free energy $\left(\Delta G^{\circ}\right)$, enthalpy $\left(\Delta H^{\circ}\right)$ and entropy $\left(\Delta S^{\circ}\right)$ during the adsorption of $\mathrm{MB}$ on $\mathrm{AC}$ were calculated. The thermodynamic parameters can be determined from the equilibrium constant $K_{L}$ which depends on the temperature [8]. The parameters $\Delta G^{\circ}, \Delta S^{\circ}$, and $\Delta H^{\circ}$ were evaluated using the expressions as [9]:

$$
\Delta G^{\circ}=\Delta H^{\circ}-\Delta S^{\circ}
$$

$\Delta H^{\circ}$ and $\Delta S^{\circ}$ correspond to the slope and intercept of a graph of $\ln K_{L}$ against $1 / K$. The thermodynamic parameters are shown in Table 2.

Samples of methylene blue and activated carbon were shaken by Benchmark H2024 ROTO-THERM MINI PLUS rotary incubator. After sorption experiment, the mixtures were separated by centrifugation using Nahita model 2640/12 centrifuge. The concentration of MB was determined by Spectronic Unicam Genesys 8 UV/VIS spectrophotometer at the wavelength of $664 \mathrm{~nm}$ in a $1 \mathrm{~cm}$ cuvette.

The amount of equilibrium adsorption, $Q_{e}(\mathrm{mg} / \mathrm{g})$, was calculated using the formula

$$
Q_{e}=\frac{\left(C_{i}-C_{f}\right) V}{w}
$$

The removal efficiency was calculated using the following equations [6]

$$
R \%=\frac{\left(C_{i}-C_{f}\right) 100}{C_{i}}
$$

where $C_{i}$ and $C_{f}$ are the initial and final (equilibrium) concentrations of the solute in solution $(\mathrm{mg} / \mathrm{L}) ; V(\mathrm{~L})$ is the volume of the solution, and $w$ is the mass of dry adsorbent $(\mathrm{g})$.

All used chemicals were of analytical grade. All experiments were made in triplicate.

\section{Effect of contact time and dye concentration}

The effect of contact time and the adsorption of MB by activated carbon were studied at $30{ }^{\circ} \mathrm{C}$ without prior $\mathrm{pH}$ adjustment $(\mathrm{pH} 4)$ at 5, 15, 60, 120, 180, 240, 300, 360, and $1200 \mathrm{~min}$. 
The adsorption was performed in a H2024 ROTO-THERM MINI PLUS incubator equipped with a temperature sensor. All adsorption experiments were made at the concentration of methylene blue 3 and $4 \mathrm{mg} / \mathrm{L}$. The model solutions were allowed to warm for 10 minutes at a given temperature until the desired sorbent suspension was added, and until the desired solution temperature was reached. From this point on, the concentration of MM after sorption was measured.

\section{Effect of $p H$}

The $\mathrm{pH}$ is one of the most important factors affecting adsorption of dyes. Both adsorbed molecules and adsorbent particles may have functional groups which are affected by the concentration of hydrogen ions $\left(\mathrm{H}^{+}\right)$in the solution and which are involved in the molecular adsorption process at the active sites of the adsorbent. The $\mathrm{pH}$ of the dye solution affects not only the surface charge of the surfaces adsorbents, the degree of ionization of the materials and the dissociation of functional groups on the active sites of the adsorbents surface, but also the structure of the dye molecule[6,10,11]. $\mathrm{pH}$ values in the range of $2-11$ were monitored for the sorption of MB dye on AC. The contact times were 60 and 180 minutes.

\section{Effect of temperature}

Temperature is a highly significant parameter in the adsorption process. Activated carbon is known for decreasing viscosity and increasing molecular motion at a higher temperature, which allows easier uptake of molecules into the pores, and caused increased adsorption at increased temperature [12]. In this study, the effect of temperature on the methylene blue by activated carbon was studied by varying the temperature between 30 and $60{ }^{\circ} \mathrm{C}$. The contact times were 60 and 180 .

In this study, Taguchi method was applied to optimize the effective parameters of methylene blue adsorption on synthetized activated carbon. Taking into account the resulting measured data of adsorption process, three different parameters of (1) the $\mathrm{pH},(2)$ concentration of methylene blue in solution and (3) contact time, were selected as the main effective parameters to be optimized. At the end of each experiment, the measured absorption values of the methylene blue were taken as a response factor according to the "greater is better" approach, because the aim was to obtain high removal of MB by adsorption on AC. The quantitation proposed by Taguchi for $\mathrm{S} / \mathrm{N}$ calculation according to these criteria is:

$$
\frac{s}{N}=-10 \log \left[\frac{1}{n} \sum_{i=1}^{n} \frac{1}{y_{i}^{2}}\right]
$$

where $y_{i}$ is experimental response $(\mathrm{R} \%), n$ is the replication number of the experiment $[13,14]$.

\section{RESULTS AND DISCUSION}

Predicting the rate at which the pollutants removal takes place in a given solid/solution system is one of the crucial factors for an effective sorption system design. The development of an appropriate model can be based on accepting a certain fundamental approach to interfacial kinetics. The formulas such as the pseudo-first (Lagergren) or pseudo-second equations are applied for correlating the kinetics data measured in many different systems [12]. The kinetics data of adsorption processes provide the key information about the efficiency of adsorption. The experimental adsorption kinetics data were obtained at $30{ }^{\circ} \mathrm{C}$ to evaluate the adsorption rate constant that controls the mechanism of $\mathrm{MB}$ dye adsorption $(3 \mathrm{mg} / \mathrm{L}$ and $4 \mathrm{mg} / \mathrm{L}$ ) from aqueous solution onto activated carbon. 
The best results were obtained from the plot of the pseudo-second-order model, whose curve fitting linear regression coefficient was much closer to unity than that of pseudo-firstorder model (Figure 1). The calculated $q_{e}$ value was reasonably close to the experimental value (3.7618 mg/g; $4.5255 \mathrm{mg} / \mathrm{g}$ respectively) indicating that MB dye adsorption on activated carbon obeyed pseudo-second-order kinetics.

Table 2 Kinetic parameters of adsorptions

\begin{tabular}{|c|c|c|}
\hline \multirow{2}{*}{ Kinetic model } & \multicolumn{2}{|c|}{ Concentration of Methylene blue } \\
\hline & $3 \mathrm{mg} / \mathrm{L}$ & $4 \mathrm{mg} / \mathrm{L}$ \\
\hline$q_{\exp }(\mathrm{mg} / \mathrm{g})$ & 3.7618 & 4.5255 \\
\hline \multicolumn{3}{|c|}{ Pseudo-first-order Model } \\
\hline$k_{1}(1 / \min )$ & $-1.1219 \times 10^{-4}$ & $-6.008 \times 10^{-6}$ \\
\hline $\mathbf{R}^{2}$ & 0.7481 & 0.6183 \\
\hline$q_{e}(m g / g)$ & 1.0569 & 1.1516 \\
\hline \multicolumn{3}{|c|}{ Pseudo-second-order Model } \\
\hline $\mathrm{k}_{2}(\mathrm{~g} / \mathrm{min} \mathrm{mg})$ & 0.0322 & 0.0417 \\
\hline $\mathbf{R}^{2}$ & 0.9988 & 0.9968 \\
\hline$q_{e}(m g / g)$ & 3.9798 & 3.9598 \\
\hline
\end{tabular}

According to [12], the pseudo-second order kinetics is usually associated with the situation when the rate of direct adsorption/desorption process controls the overall sorption kinetics. The rate of the ion exchange reaction occurring on the surface is responsible for the removal kinetics and that the kinetic order of this reaction is two with respect to the number of adsorption sites available for the exchange. The corresponding characteristics of fitted models are summarized in Table 2. Approximately $50 \%$ of the initial concentration of MB was removed in 15 minutes, which indicates a strong affinity of cationic MB and activated carbon.

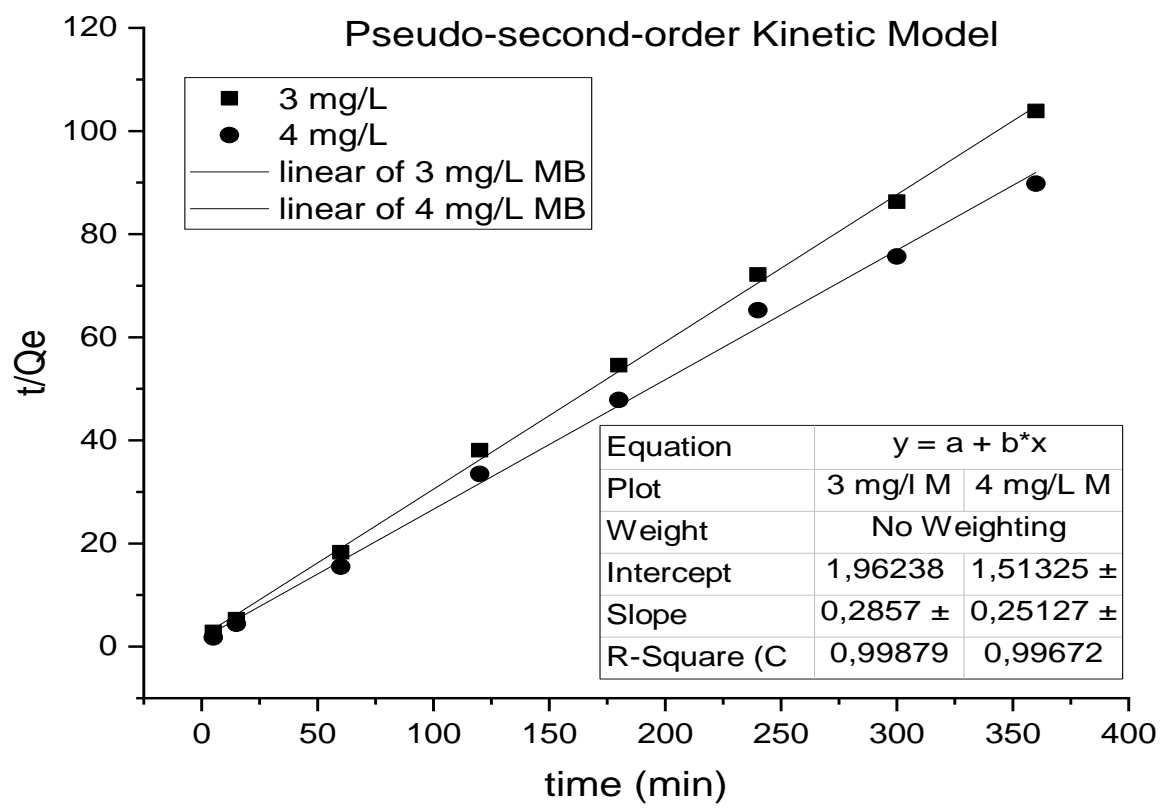

Figure 1 Kinetic model for sorption process - pseudo-second order (initial concentration 3 and $4 \mathrm{mg} / \mathrm{L}$ )

The experiments show that the minimum time interval for adsorption is 300 minutes, during which it is necessary to leave the sorbate with the sorbent in mutual contact with each other. 
The thermodynamic parameters of activated carbon are shown in Table 2. Negative value of $\Delta G^{\circ}$ establish the feasibility of adsorption which occurs spontaneously and favourably with the increase in temperature, similar result for $\mathrm{AC}$ can be found in [15]. The endothermic nature of MB sorption onto AC was confirmed by the positive values of $\Delta H^{\circ}$. Positive value of entropy $\Delta S^{\circ}$ indicate the increased randomness at the solid-solution interface during the fixation of adsorbate on the active sites of the adsorbent.

\begin{tabular}{|c|c|c|c|c|}
\hline Temperature & $\begin{array}{c}\Delta G^{\circ} \\
(\mathrm{kJ} / \mathrm{mol})\end{array}$ & $\begin{array}{c}\Delta \mathbf{H}^{\circ} \\
(\mathrm{KJ} / \mathrm{mol}) \\
\end{array}$ & $\begin{array}{c}\Delta \mathbf{S}^{\circ} \\
(\mathbf{K} / \mathbf{J} / \mathbf{m o l})\end{array}$ & $\mathbf{R}^{2}$ \\
\hline $30^{\circ} \mathrm{C}$ & -4.3652 & \multirow{4}{*}{0.1482} & \multirow{4}{*}{14.4133} & \multirow{4}{*}{0.9999} \\
\hline $40{ }^{\circ} \mathrm{C}$ & -4.5093 & & & \\
\hline $50^{\circ} \mathrm{C}$ & -4.6534 & & & \\
\hline $60^{\circ} \mathrm{C}$ & -4.7976 & & & \\
\hline
\end{tabular}

\section{Effect of contact time and dye concentration}

The methylene blue adsorption capacity increased significantly with the increase in time from 0 to $1200 \mathrm{~min}$. Adsorption capacity stops increasing upon reaching approximately $300 \mathrm{~min}$. The effects of initial concentrations of MB at different initial concentrations of 3 and $4 \mathrm{mg} / \mathrm{L}$ can be seen in Figure 2. The adsorption amount increases with increasing the initial concentration. The lower removal efficiency in $300 \mathrm{~min}$ is $60 \%$ at a MB concentration of $4 \mathrm{mg} / \mathrm{L}$ and $85 \%$ at $3 \mathrm{mg} / \mathrm{L}$. At lower MB concentration, the higher removal efficiency was achieved.
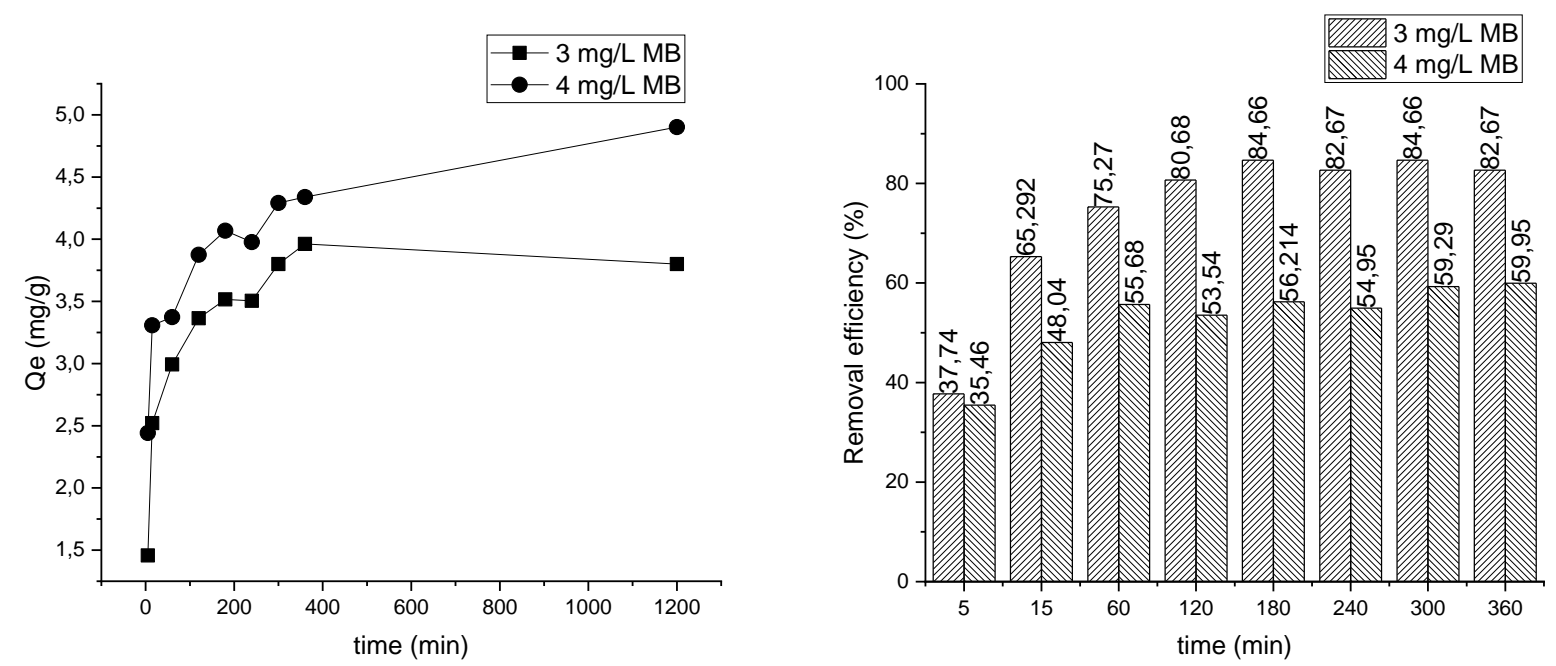

Figure 2 Effect of contact time and dye concentration

\section{Effect of $p H$}

The results of the $\mathrm{pH}$ studies at different $\mathrm{pH}$ values are shown in Figure 2. $\mathrm{pH}$ values in the range of 2 - 11 were monitored for the sorption of MM dye on AC. The contact times were 60 and 180 minutes. The measurements were performed at a temperature of $30^{\circ} \mathrm{C}$, at the initial concentration MB $4 \mathrm{mg} / \mathrm{L}$. Adsorption capacity of activated carbon increased with increasing $\mathrm{pH}$, and reached the maximum level at the $\mathrm{pH}$ of 11, in both cases the highest efficiency was found at $\mathrm{pH} 11$. 

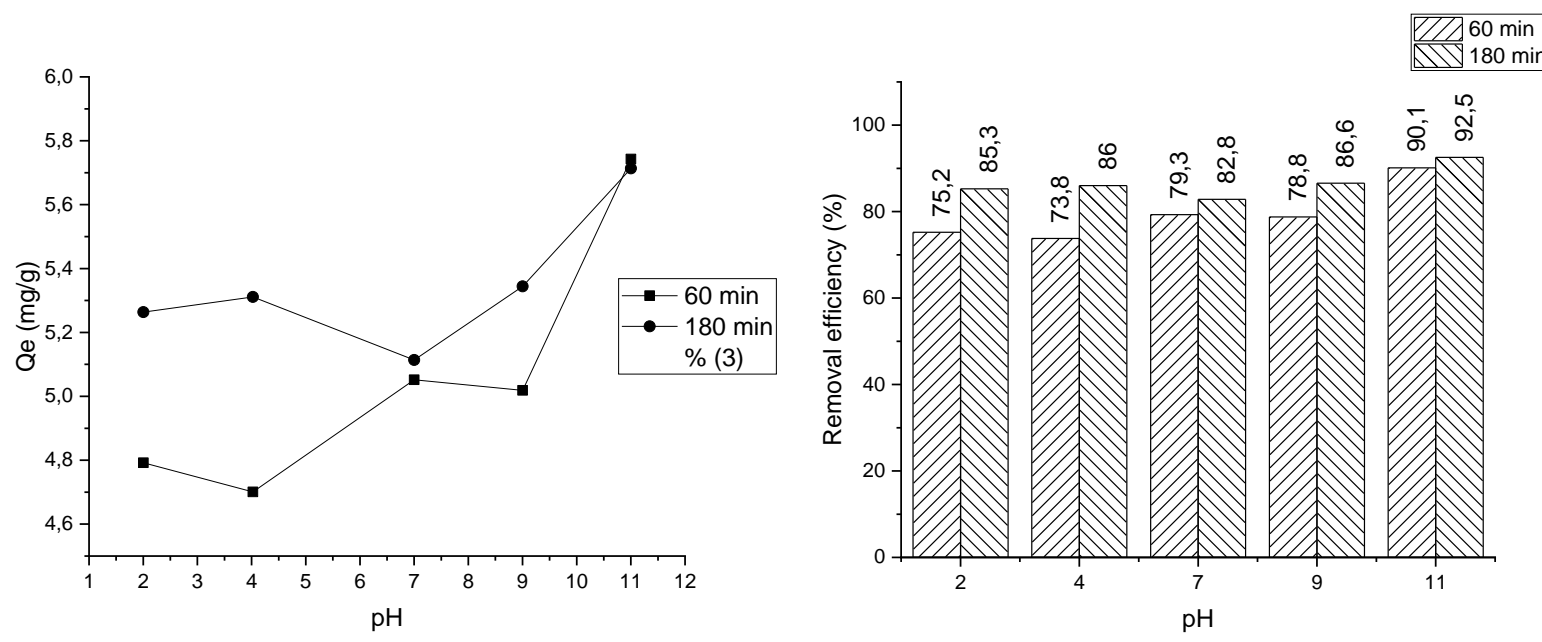

Figure 3 Effect of various initial $p H$

\section{Effect of temperature}

The effect of temperature on adsorption of MB on activated carbon was observed at four different temperatures: $30,40,50$ and $60{ }^{\circ} \mathrm{C}$ in 60 and 180 minutes. The results indicate that when the temperature increased from $30^{\circ} \mathrm{C}$ to $60^{\circ} \mathrm{C}$, the adsorption capacity of methylene blue onto AC increased slightly from $5.04 \mathrm{mg} / \mathrm{g}$ to $5.61 \mathrm{mg} / \mathrm{g}$ for $60 \mathrm{~min}$. contact time and from 5.94 to $3.37 \mathrm{mg} / \mathrm{g}$ in time $180 \mathrm{~min}$. Therefore, higher temperature facilitated the adsorption of $\mathrm{MB}$ on $\mathrm{AC}$.
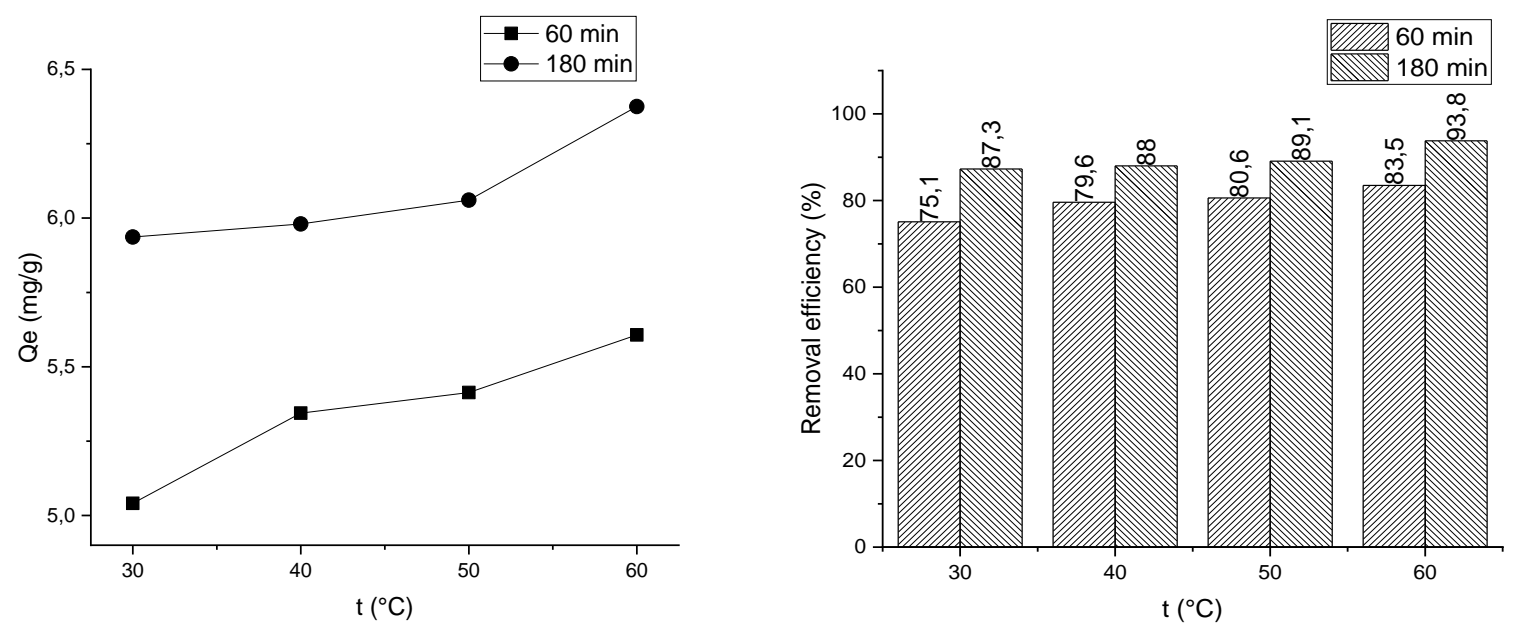

Figure 4 Effect of initial temperature

\section{Designing of experiments adsorption by Taguchi method}

In this method, orthogonal arrays are used to perform necessary experiments. The factor and their levels are showed in Table 4. For the four factors and two levels, L 8 orthogonal array was chosen. To analyse the experimental result, the interactions among the factors were not considered, and the "signal/noise" $\mathrm{S} / \mathrm{N}$ ration was computed for each experiment. 


\begin{tabular}{|c|l|c|c|}
\hline \multicolumn{2}{|c|}{ Table 4 The factor and their levels } \\
\hline Symbol & \multicolumn{1}{|c|}{ Factor } & \multicolumn{2}{c|}{ Level } \\
\hline & & 1 & 2 \\
\hline $\mathrm{A}$ & Temperature $\left({ }^{\circ} \mathrm{C}\right)$ & 30 & 40 \\
\hline $\mathrm{B}$ & $\mathrm{pH}$ & 60 & 7 \\
\hline $\mathrm{C}$ & Time (min) & 3 & 4 \\
\hline $\mathrm{D}$ & Concentration of $\mathrm{MB}(\mathrm{mg} / \mathrm{L})$ & \multicolumn{2}{|c}{} \\
\hline
\end{tabular}

The results of the experiments and $\mathrm{S} / \mathrm{N}$ ratio are given in Table 5. For the Taguchi method, it holds that the higher the $\mathrm{S} / \mathrm{N}$ proportion on a level, the more appropriate that level of the factor. The highest $\mathrm{S} / \mathrm{N}$ ratio is therefore in the case of the factor related to the desired conditions. Based on the S/N results, the optimum conditions in the process of adsorption of $\mathrm{MB}$ from aqueous solutions using activated carbon are the temperature at $40{ }^{\circ} \mathrm{C}, \mathrm{pH} 7$, contact time of $60 \mathrm{~min}$ and concentration of methylene blue of $4 \mathrm{mg} / \mathrm{L}$.

\begin{tabular}{|c|c|c|c|c|c|c|}
\hline \multicolumn{6}{|c|}{ Table 5 Experimental results for L8 } \\
\hline Experiment & $\mathbf{R}_{\mathbf{1}} \%$ & $\mathbf{R}_{\mathbf{2}} \%$ & $\mathbf{R}_{\mathbf{3}} \%$ & $\begin{array}{c}\text { Standard } \\
\text { deviation }\end{array}$ & Variance & S/N ratio \\
\hline $\mathbf{1}$ & 76.62 & 76.92 & 75.15 & 0.95 & 0.90 & 37.64 \\
\hline $\mathbf{2}$ & 75.9 & 75.56 & 74.18 & 0.915 & 0.83 & 37.52 \\
\hline $\mathbf{3}$ & 83.27 & 83.98 & 84.14 & 0.46 & 0.21 & 38.46 \\
\hline $\mathbf{4}$ & 82.79 & 83.48 & 83.82 & 0.53 & 0.28 & 38.42 \\
\hline $\mathbf{5}$ & 79.63 & 79.27 & 80.02 & 0.38 & 0.14 & 38.02 \\
\hline $\mathbf{6}$ & 87.96 & 87.3 & 86.99 & 0.50 & 0.25 & 38.83 \\
\hline $\mathbf{7}$ & 81.03 & 80.99 & 80.3 & 0.41 & 0.17 & 38.15 \\
\hline $\mathbf{8}$ & 79.29 & 79.69 & 80.03 & 0.37 & 0.14 & 38.03 \\
\hline
\end{tabular}

\section{CONCLUSION}

The present manuscript studies the dynamic behaviour of the adsorption of methylene blue onto activated carbon used as adsorbent. Batch experiments were carried out to investigate the effect of different factors on the removal of cationic MB, including the initial concentration, $\mathrm{pH}$, temperature, and contact time.

Taguchi method was used to investigate the effect of control factors on dye removal. The optimal conditions were temperature at $40{ }^{\circ} \mathrm{C}, \mathrm{pH} \mathrm{7}$, contact time $60 \mathrm{~min}$ and concentration of methylene blue $4 \mathrm{mg} / \mathrm{L}$. The kinetic studies showed that the pseudo-second order model presented a good adjustment for adsorption process. The negative values of $\Delta G^{\circ}$ and positive values of $\Delta H^{\circ}$ and $\Delta S^{\circ}$ indicate that the dye adsorption process is spontaneous and endothermic.

\section{References}

[1] C. LIU, A. M. OMER and X. KUN OUYANG. 2018. Adsorptive removal of cationic methylene blue dye using carboxymethyl cellulose/k-carrageenan/activated montmorillonite composite beads: Isotherm and kinetic studies. Int. J. Biol. Macromol., Vol. 106, pp. 823-833. doi: 10.1016/j.ijbiomac.2017.08.084.

[2] N. R. J. HYNES et al. 2020. Modern enabling techniques and adsorbents based dye removal with sustainability concerns in textile industrial sector -A comprehensive review. J. Clean. Prod., Vol. 272, p. 122636. doi: 10.1016/j.jclepro.2020.122636. 
[3] Y. ZHOU, J. LU, Y. ZHOU and Y. LIU. 2019. Recent advances for dyes removal using novel adsorbents: A review. Environ. Pollut., Vol. 252, pp. 352-365. doi: 10.1016/j.envpol.2019.05.072.

[4] M. A. HASSAAN and A. EL NEMR. 2017. Health and Environmental Impacts of Dyes : Mini Review. Am. J. Environ. Sci. Eng., 1(3), pp. 64-67. doi: 10.11648/j.ajese.20170103.11.

[5] A. ESFANDIARI, T. KAGHAZCHI and M. SOLEIMANI. 2012. Preparation and evaluation of activated carbons obtained by physical activation of polyethyleneterephthalate (PET) wastes. $J$. Taiwan Inst. Chem. Eng., 43(4), pp. 631-637. doi: 10.1016/j.jtice.2012.02.002.

[6] A. ELSAGH, O. MORADI, A. FAKHRI, F. NAJAFI, R. ALIZADEH and V. HADDADI. 2017. Evaluation of the potential cationic dye removal using adsorption by graphene and carbon nanotubes as adsorbents surfaces. Arab. J. Chem., Vol. 10, pp. S2862-S2869. doi: 10.1016/j.arabjc.2013.11.013.

[7] M. WAWRZKIEWICZ, M. WIŚNIEWSKA, V. M. GUN'KO and V. I. ZARKO. 2015. Adsorptive removal of acid, reactive and direct dyes from aqueous solutions and wastewater using mixed silicaalumina oxide. Powder Technol., Vol. 278, pp. 306-315. doi: 10.1016/j.powtec.2015.03.035.

[8] H. LAKSACI, A. KHELIFI, M. TRARI and A. ADDOUN. 2017. Synthesis and characterization of microporous activated carbon from coffee grounds using potassium hydroxides. J. Clean. Prod., Vol. 147, pp. 254-262. doi: 10.1016/j.jclepro.2017.01.102.

[9] U. A. EDET and A. O. IFELEBUEGU. 2020. Kinetics, isotherms, and thermodynamic modeling of the adsorption of phosphates from model wastewater using recycled brick waste. Processes, $\mathbf{8}(6)$, doi: 10.3390/PR8060665.

[10] C. MUTHUKUMARAN, V. M. SIVAKUMAR and M. THIRUMARIMURUGAN. 2016. Adsorption isotherms and kinetic studies of crystal violet dye removal from aqueous solution using surfactant modified magnetic nanoadsorbent. J. Taiwan Inst. Chem. Eng., Vol. 63, pp. 354-362. doi: 10.1016/j.jtice.2016.03.034.

[11] Y. H. LIN and J. Y. LEU. 2008. Kinetics of reactive azo-dye decolorization by Pseudomonas luteola in a biological activated carbon process. Biochem. Eng. J., 39(3), pp. 457-467. doi: 10.1016/j.bej.2007.10.015.

[12] W. PLAZINSKI, W. RUDZINSKI and A. PLAZINSKA. 2009. Theoretical models of sorption kinetics including a surface reaction mechanism: A review. Adv. Colloid Interface Sci., 152(1-2) pp. 2-13. doi: 10.1016/j.cis.2009.07.009.

[13] N. ZIAEIFAR, M. KHOSRAVI, M. A. BEHNAJADY, M. R. SOHRABI and N. MODIRSHAHLA. 2015. Optimizing adsorption of $\mathrm{Cr}(\mathrm{VI})$ from aqueous solutions by $\mathrm{NiO}$ nanoparticles using Taguchi and response surface methods. Water Sci. Technol., 72(5), pp. 721729. doi: 10.2166/wst.2015.253.

[14] R. A. CANALES-FLORES and F. PRIETO-GARCÍA. 2020. Taguchi optimization for production of activated carbon from phosphoric acid impregnated agricultural waste by microwave heating for the removal of methylene blue. Diam. Relat. Mater., Vol. 109, No. August, p. 108027. doi: 10.1016/j.diamond.2020.108027.

[15] C. SILVEIRA, Q. L. SHIMABUKU-BIADOLA, M. F. SILVA, M. F. VIEIRA and R. BERGAMASCO. 2020. Development of an activated carbon impregnation process with iron oxide nanoparticles by green synthesis for diclofenac adsorption. Environ. Sci. Pollut. Res., 27(6), pp. 6088-6102. doi: 10.1007/s11356-019-07329-7.

\section{ORCID}

$\begin{array}{ll}\text { Alica Pastierová } & \text { 0000-0003-1442-9652 } \\ \text { Maroš Sirotiak } & 0000-0003-1487-801 X\end{array}$ 